\title{
Erratum: Elansary et al., 5-Aminolevulinic Acid and Soil Fertility Enhance the Resistance of Rosemary to Alternaria dauci and Rhizoctonia solani and Modulate Plant Biochemistry. Plants 2019, 8, 585
}

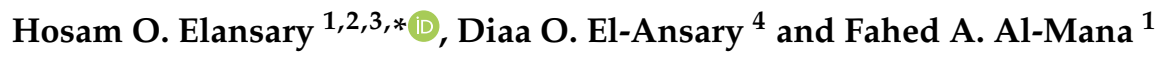 \\ 1 Plant Production Department, College of Food and Agricultural Sciences, King Saud University, \\ P.O. Box 2455, Riyadh 11451, Saudi Arabia; falmana@ksu.edu.sa \\ 2 Floriculture, Ornamental Horticulture, and Garden Design Department, Faculty of Agriculture (El-Shatby), \\ Alexandria University, Alexandria 21526, Egypt \\ 3 Department of Geography, Environmental Management, and Energy Studies, University of Johannesburg, \\ APK campus, Johannesburg 2006, South Africa \\ 4 Precision Agriculture Laboratory, Department of Pomology, Faculty of Agriculture (El-Shatby), \\ Alexandria University, Alexandria 21526, Egypt; diaaagri@hotmail.com \\ * Correspondence: helansary@ksu.edu.sa; Tel.: +966-0581216322
}

Received: 24 December 2019; Accepted: 26 December 2019; Published: 31 December 2019

The authors wish to make the following corrections to their paper [1]. The number of the funding agency in the Funding and Acknowledgments sections is incorrect. The details of the corrections are described below.

1. Funding: The study was funded by King Saud University through the Researchers Supporting Project number (RSP-2019/118).

2. Acknowledgments: The authors thank King Saud University through the Researchers Supporting Project number (RSP-2019/118).

These changes do not affect the conclusion of the paper. The authors would like to apologize for any inconvenience this might have caused.

\section{Reference}

1. Elansary, H.O.; El-Ansary, D.O.; Al-Mana, F.A. 5-Aminolevulinic Acid and Soil Fertility Enhance the Resistance of Rosemary to Alternaria dauci and Rhizoctonia solani and Modulate Plant Biochemistry. Plants 2019, 8, 585. [CrossRef] [PubMed]

(C) 2019 by the authors. Licensee MDPI, Basel, Switzerland. This article is an open access article distributed under the terms and conditions of the Creative Commons Attribution (CC BY) license (http://creativecommons.org/licenses/by/4.0/). 